\title{
Thinking of Film Education with Media Convergence Background
}

\author{
Jianxun $\mathrm{Wu}$ \\ Management Department \\ Beijing Film Academy \\ Beijing, China
}

\begin{abstract}
The trend of media convergence has brought many changes to the film industry, changes that are inevitable and need to adapt to education. Film education can be understood in two areas, including talent education and medium education. We need to develop the film education with new media and new technologies. Some of the problems may exist in the current wave of new media. We need to extract some ways to improve our education and provide effective suggestions for film education.
\end{abstract}

Keywords-media convergence; film education; industry change

\section{INTRODUCTION}

In Andrew Nachison opinion, the so-called media convergence is "the operation, cultural alliance strategy between print, audio, video, and interactive digital media organizations." Some scholars from the broad and narrow sense to definite it, "Broadly speaking, media convergence should includ a collection of the elements and integration of all media, not only includes the integration of media forms, further comprising integration of communication means, structure, function and ownership; and from the narrow point of view, media convergence only contains integration of different forms of media, such as news blog, e-magazines. " Some scholars have pointed out that the integration of media will show two different development trend, On the one hand it concerned the traditional media, asking them to make full use of the new forms of communication and technology, and explore a variety of management tools, and ultimately integration with the Internet; The other is for the new media, asking them to give full play to their advantages of interactivity, using advanced communication channels to spread, so as to achieve the ultimate purposes which rid itself of the shackles of traditional media. These concepts have made the phenomenological description of media convergence's status and prospects.

On the film industry, in recent years, with the development of new media, film industry continuous integration with new media, one hand the Internet means of communication, the Internet platform is continually impact on the traditional film industry processes; The other hand, generation of "Net Generation" film business, film director, movie themes, moviegoers, also changing the habits of the movie industry. In such an environment, film education as the cornerstone of the development of the film industry, of course, also need to adapt to the trend of media convergence, how to make the film education to new heights under new situation need films educators constantly thinking.

\section{MEANING OF FILM EdUCATION}

This article will discussion film education into two categories.First is film talent education which through teaching film knowledge, teaching skills for students to adapt each link of the film industry, training the needed talent for film industry; Second is make the film as a medium and educational tools, through the spread of film to enhance the National Artistic View, enhance the people accomplishment and train the film market, at the same time let the movie as a link of to promote international exchange. Two areas are closely related and complement each other. Talent education can be understood as training creation talent, it's the work of the film production side, but the film as a medium is to develop a movie audience, it is to create the foundation for the development of the film industry. With economic development, people's living standards continue to improve, compared with economic construction and cultural construction is still gaps the film as an important art form, there is a growing need of art appreciation of people to a certain extent, people's viewing habits and the need to cultivate and guide. Emerging good works will attract more viewers to the theater, and the high level of appreciation of the audience will inevitably promote the movie production to continuous improvement so that can fit the needs of the people. Therefore, the two areas of the film education appears to be two aspects, but in fact mutually reinforcing and inclusive.

\section{MEDIA CONVERGENCE BRINGS FILM EdUCATION OPPORTUNITIES AND CHALLENGES}

In the context of media convergence film education creates new opportunities and challenges, including.

\section{A. Promote Industrial Change}

With the backdrop of media Convergence many new technologies have emerged, new technology being used in various industries provide a new power to industrial upgrading, driven by the new power the industry itself need to 
adjustment of the industry chain timely. Under Media Convergence background film industry is also facing industrial change. Performance as the investment and financing methods changes, the new method of crowdfunding, platforms financing emerging; diverse creative material and forms, network IP are more popular; channels of each link augmented, multi-channel business strategy appears; film sales cycle more diversified, mobile ticketing, online seat selection and other new ways endless; web cinema's appear gradually began to snatch viewers with entity cinema. Media convergence has effectively brought great changes to the film industry, how to deal with this round of industrial revolution, so that education can development with Industrial synchronous is one of the problems faced by film education.

\section{B. Diversification of Education Channels}

The most change which bring from Media convergence for education may be the change of channel, the main way to acquire knowledge in traditional education is books, the emergence of new media enable learners not only able to view the book, but also learn through online video, online community platforms. New Ways are more convenient, knowledge will get more accessible and information coverage wider. New media brings change not just formal education, but also includes changing channels, content, etc., film education as a skillful discipline, how to deal with the impact of new media is a problem that film education must be faced.

\section{Technological Development Polarization}

With the development of new media, new techniques are emerging, the traditional view of the method are being impacted and challenged. For the film industry, technology and equipment updates faster, high-end operation of the device requirements more skill, demanding more specialized technical operations personnel; At the same time, small digital cameras, editing digital synthesis technology, more and more people join the creative team. Make movie for nonprofessionals is no longer elusive. The reduce of film technology's barriers to entry, leveled from the film novice and master. Technological innovation necessary requirement film education to constantly change, taking into account how high-tech learning and respond to the risks of lowering the threshold for film education is an unavoidable problem.

\section{Rapid Transmission of Information}

New media representative's emergence of the Internet to break the space constraints, people can communicate anytime, anywhere. In this context, the transmission of information faster, more informative, cultural exchanges are more frequent. Film as an important manifestation of cultural products, has unshirkable responsibility for cultural exchange, How to use movies to promote culture and communication, how will the movie frame into bridge of foreign exchange is the problem which needed to solve about film education. At the same time the Internet makes the exchange between educators easier, the interaction between domestic and foreign universities is more convenient, how to use the Internet to promote film education on a global scale has become the subject of movie educators.

\section{A NuMBER OF ISSUES THAT EXIST AT PRESENT FILM EDUCATION}

The emergence of new opportunities and challenges give $\mathrm{t}$ film education an opportunity to upgrade.Film education should be adjustmented and changed on specific issues in new environment to.at present, there are several problems in film education to carry out, mainly for the following aspects.

\section{A. Lack of Complex Interdisciplinary Talents}

The current number of film professional in colleges and universities, a relatively large number of professional personnel training in animation, directing, acting, etc., and management, project planning, professional training and other digital cinema technology is obviously insufficient, the problem of irrational professional structure more prominent.

\section{B. Teaching, Research and Creating Relative Separation}

Film education mainly in practice education, in the tradition of teaching mode, teachers often use practical experience as the main teaching content, curriculum standardization has not yet reached. And film theoretical study and film-making is out of state in a long-term, creator are lack of theory, plunge into the creative practice and attend to the theoretical study; Researchers known nothing about creation, buried in books and lack of practical experience. This results in status quo that film education,research and create relatively isolated, it will not only affect the sustainable development of the film industry, there may impede film education to enhance their own power.

\section{Lack of High-Radiating Film Education System}

Under media convergence environment, "Net Generation" is the film's main target market, and the research of the " Net Generation"'s characteristics, market development efforts are still not enough, the film education system has not been to the level of the whole society. Specifically, the film needs to constantly cultivate the market to continue to tap new target market, currently film education system only be understood as a simple university film education, film education for primary and secondary schools, the degree of attention to social film education is still not enough, simply concerned with the present and the future is still limited to efforts to cultivate the market. Currently film education in schools, universities and social slightly disjointed, primary and secondary schools without adequate enlightenment work about movie, movie College do not have enough personnel training time, many filmmakersdo not have ways to continued learning. These are the problems that film education strategy system exists.

\section{Audience's Art Appreciation Level Should Be Improved}

With the prosperity and development of the film, the market gradually expanded, more and more market potential will be tapped, but now the audience for the film is still not get the level of appreciation, that means movie entertainment, and artistic content for films lack a deep understanding, this can be found from fan phenomenon, IP phenomenon, variety show movies etc. Audience art appreciation is limited, 
because the efforts on film education are still not enough, the range of film education also not wide enough, the use of film as an intermediary f still unreasonable, films did not play well the mission of cultural propaganda.

\section{E. Filme Education Degree of Internationalization Is Still Not Enough}

Internet deepened, accelerated globalization, the international trend of the film industry appears. As a basis for the development of the film industry, the degree of internationalization of the education has not keep up,compared to other disciplines the number of exchange students about film professionals is still small; cooperation and exchanges between world-class film universities closeness. As a communication tool can across language barriers, filmcshould become an important carrier of international communication.

\section{The Necessity to EnHance Movie EduCATION UNDER THE BACKGROUND OF MEDIA INTEGRATION}

Why is media convergence can bring new development opportunities, how to seize the new situation of industrial development,these are new issues of film education faces within the current period. By analyzing the problems of the current film education we know that it needs to change, enhance our education has become a necessity.

\section{A. We Need to Continuously Upgrade Film Education to Train More Professionals}

Technology upgrading, industrial upgrading, will inevitably lead to demand for talent increases. The emergence of new technologies requires us to trained people who can master the new media technologies, they can complete the stated objectives by using new media rational and effective; Upgrading of industries, requires personnel have the whole industry chain field of vision; Exchanges increased, need more talents who both understand movies,cultural and foreign language to do film publicity work; channels Changed, requiring more film talent who can take full advantage of emerging channels to work .etc. Education is the output library of movie film talent, Training pluralistic talents that can better adapt the development of the film industry will undoubtedly increase the lifting power of film education, film education needs to find the way to adapt quickly under the pressure of demand for talent.

\section{B. We Need to Enhance Our Education to Accommodate More Diverse of Technical Means}

Film as an technology-driven art, continuous development as technology promote, with the technical means gradually, the audience get more realistic viewing experience; At the same time, Facilitation and Digitizing making movie create lowering the threshold, created new challenges for professional movie industry. Under this context, first the film education needs to teach new technology, to develop high-end film and technical personnel. Currently at the technical level, the gap is still large compared with other countries with Hollywood, train a number of high-end talent is necessary to ensure national film industry development; Second, we must increase the quality of film professionals create content to against the risk of lowering the threshold.Therefore, to enhance film education is imperative.

\section{We Need to Enhance Our Education to Meet the Needs of A Richer Culture}

With the growing economic level, people's spiritual needs for entertainment continues to grow, but at this stage the phenomenon still exists which there is not enough entertainment ways.film is one of the cultural products which people often contact. it can be an effective tool for the promotion of cultural ideas, and it can enhance art appreciation Level of people. We can assume that the film education undertake the important mission of enhance people's art view, while continuing to expand and nurture the film market, thus growing film industry.

\section{We Need to Enhance Film Education in Order to Promote More Extensive International Exchanges}

In recent years, exchanges increase within international deepening, movies from different countries are emerging in the international arena, but there are still differences between these movies. Along with a more open environment, film exchange should be more extensive; At the same time, the Internet promotes the exchange, student exchange, cooperation projects, cooperative education require to increase educational content.

\section{SOME COUNTERMEASURES TO ENHANCE THE FILM EDUCATION}

By analyzing the need to upgrade the film education under the background of media convergence, we conclude we need to enhance our film education urgency, and made a number of film education problems exist in the current context. In the current environment,we need to find effective ways to enhance film education reasonable and effective, this chapter describes some of the ways which may enhance our film education through two areas, hoping to help development for the film under the background of media convergence.

\section{A. Adjust Movie Training Mode}

With the constant change of industrial structure, all sectors of the film industry's rising demand for talent, the ability to adapt to the new culture industry trends movie talent to become a top priority of education.Changing industrial structure requires more complex film industry talents ,talent is no longer the owner of specific skills, but with a number of professional skills, talent need to understanding of all aspects of the whole industry. Thus this background film education should focus on developing integrated talent, broaden the students' knowledge, to guide students to understand the characteristics of various aspects of the film industry, the culture of the people has the whole industry chain vision.

1) Interdisciplinary training talents: Enhance crossdisciplinary construction, efforts to shape the fusion of development of the film with other disciplines, students with multidisciplinary vision. Undergraduate professional 
disciplines can strengthen the knowledge base, increase the knowledge of other disciplines covered, enrich students' horizons; the graduate level can interdisciplinary admissions, such as selecting students with a background in economics so that after they learning film systematic, students can Reflections on the problems of the film industry based on the laws of film economic development. Or choose the students with technology background, so that students can mastered Internet technology combined with the film industry to find new technology or research development means, promote the development through technology. Through cross-disciplinary culture can enrich the film talent reserves, from more angle to boosting the development of the film industry.

2) Compound whole industry chain talents: Cultivate high-quality talents, can also development and research between universities, based on the demand of industrial chain, according to the practical issues facing the film industry, choose to cooperate with research institutions to conduct joint development of projects, such as in the movie Information system Construction side, using film institutions' advantages of understanding of the film industry to make project together with institutions which has advantages of information management, through multi-party cooperation to work out effective tool to assist in the development of the film industry, while fostering the specific tools to master the method can effectively solve the phenomenon of industrial development of talent for specific problems.Or to cooperate with new media companies, under the support of large data to make research.

\section{B. Teaching, Researching and Creating Joint Reform}

With the emergence of new media and the expansion of industrial scale, the movie College enrollment increased year by year, the number of students for the emergence of new growth and the environment, the original curriculum reform needs to be adaptive to enhance the soft power of film education.

1) Improve teaching and thinking patterns: New media makes diversity way to obtain knowledge, which is a challenge for traditional education. Therefore, to change the traditional mode of thinking and teaching may better meet the challenges brought about by the Internet. From thinking in terms of teaching, teachers no longer have a single function to impart knowledge, speed and breadth of new media for the dissemination of knowledge has far exceeded the level of teachers can be achieved, then the teachers should pay more attention to guide the students that teach students ways and means to enhance incentives for students to improve selfmotivation; from teaching mode of speaking, the use of new media device to interact with students in the classroom no longer rely only on books, to take advantage of new media tools to improve teaching; outside the classroom full the use of WeChat,Weibo and other new social tools to interact with students.

2) Promoting the integration of teaching, researching and creating: Film talent in university education is divided into three parts, the film studies, including the study of film theory, film analysis method, film development forecasting; part of film-making, mainly for film practice, guiding students to participate in the actual operation of the film, learning the specific skills; the third part is teaching film, mainly impart knowledge and practical skills related to the movie. Film as a special art form, teaching, creating and researching are relatively independent parts, with the industrial revolution and the development of forms of education, teaching, research and creating need for deepening fusion of through education consolidate research and creation foundation, through pioneering research to create new ideas, and research to boost the creation of practice development. Therefore, film education need to open the "teach-based, research driven create, create assistant research " mode.

3) Promote Reform of Course features: In order to adapt to students gradually expand the scale, it is necessary to open education model has the characteristics of film education, highlighting the film's artistic qualities. As can be: (1) conform to the trend of media convergence, open new technical courses, so that students can master the latest technology trends; (2) establish a standardized curriculum systerm, students can learn the same architecture knowledge even teacher's own different experience, reinforce the student's basic theory; (3) increase the knowledge of education, enrich students from different disciplines and art forms of knowledge acquired, so that students have a more broad vision for the future creation of pioneering ideas; (4) follow with industry trends, adds latest industry trends courses regular, so that students can thinking in times; (5) considering opening classic courses on new media, construction Mu class platform that enables a wider range of film education universal. (6) to take advantage of the new medium of the Internet to carry out mixed mode online and offline curriculum, classroom open cloud, cloud course, try to spot changes in the form of classroom discussion class, and the specific knowledge and learning into the cloud.

\section{Establish A Complete Film Education System}

1) Strengthen the popularity of the movie of different sectors and social roles: For different social groups to carry out an appropriate film education courses, including students and teachers, families, various types of community groups, university students and the general public. The purpose of such programs is to enhance the film's awareness and appreciation, broaden knowledge of the masses and enrich people's spiritual life. In universities ,primary and secondary schools open the General Education of movie, comprehensive university can make General Education in non-television disciplines, this is to broaden their interests and improve their level of art appreciation. Film education in primary and secondary education can increase in related professional teachers and courses ,they can open film appreciation courses and schools film festival, encouraging students to learn movie, develop their interest in the film from an early age.These 
measures can make the system of film education coverage broader. While strengthening the continuing education for filmmakers, using of alumni, network community and other measures to create exchange platform and learning sites of film talent, create a unique spiritual home, so that people are able to get the chance to continuou learning and improvement.

2) Create new media education system: We can create a unique Internet Movie education, create film programs on the internet, put the main content of education and the classic movie content into the official platform for the public to learn. Encourage more movie exchanges and reviews on Internet, so that the Internet can become a new front of film education research. As can offer online classes course for those who have no time to study live, this can be more flexible for improve learning. On internet they not just learning by Internet video, but can learn in the form of classes, online course on learners still have their own students to communicate.

\section{To Boost The Film As A Medium of Cultural Transmission}

Film as a communication tool that can break the language barrier, it can pass unique symbol through picture, sound and stories to the audience. So we should takes full advantage of this feature, make film as a medium of communication between countries.

1) Popular film art, enhance the level of art appreciation referendum: Film as an art accepted form, is an important entertainment program of people life, with the improvement of people's living standards, the spiritual and cultural needs are growing. Therefore, give full play to the characteristics of the film, to strengthen the film for enhancing the quality of the people is a supposed function, use film to serve the community can take measures include: (1) efforts to promote the movie into schools, into the community, into the rural areas, etc., taking advantage of new media channels to expand the amount of play and coverage. Selecte outstanding videos to show, through the film into the grass roots, not only enrich people's entertainment life, but can passed excellent cultural quality, also can take to promote the viewing population growth; (2) set up a regular movie lectures to teach film knowledge, and put the lecture content on the Internet, increase network interaction. In order to increase people's artistic accomplishment, foster artistic quality of people, enhance people's interest in the arts, the cinema as an effective tool for quality education. (3) enhance the popularity work of the movie, such as writing books about movies, building characteristics theaters, like the University theaters, art cinemas, etc. In these ways and means to strengthen and enhance the level of art appreciation of the people, for the film culture audience.

2) Build own characteristics, strengthen the exchange function: On the one hand, to strengthen cultural exchange of countries through films, make film as the main link of cultural exchanges that can promote mutual of nation's culture, through the dissemination of specific national film can effectively deliver national symbol, and enhance the national image. On the other hand, film can be as a tool for strengthening international cooperation, such as cooperation in running schools, co-produced, co-Film Festival to promote the film communicate through these forms to enhance film spread worldwide.

New media brings not only Change of tools, but change about thinking and content. Film education in China started relatively late compared to Western countries, we still need to learn and improve. Media integration provides us a good opportunity; hope to enhance the Chinese film industry by development of film education.

\section{REFERENCES}

[1] Hou Guangming, "Do a world-class film education," People's Daily.2012-1-6(017)

[2] Tong Qifu, "Reflections on the Professional Education Development film at film's power goals," Journal of Beijing Film Academy,2014(4).

[3] Choi Jung-jen, "Digital Age film education-Experiences and Reflections Korean Movie Education,” Modern Communication, 2015(3).

[4] Donald • J • Chak Pola, "Trends and challenges in the international film and television education development," Journal of Beijing Film Academy,2010(4).

[5] Yuan Youdi, "On the feature film and Practice in College Students' General Education path," Contemporary Cinema,2013(4).

[6] Lu Yuanzhen, "Internet bring what to the cultural industry," Policy Research \& Exploration,2015(4). 